\title{
Yenidoğan Buzağı İshallerinin Önemli Viral Etkenlerinden Caliciviruslar
}

\author{
İlke Karayel Hacıŏglu, Feray Alkan \\ Ankara Üniversitesi Veteriner Fakültesi Viroloji Anabilim Dalı
}

Geliş Tarihi / Received: 26.10.2018, Kabul Tarihi / Accepted: 15.11.2018

\begin{abstract}
Özet: Sı̆̆ır yetiştiriciliğinin önemli hastalıklarından biri olan yenidoğan buzağı ishalleri virus, bakteri, protozoon gibi birçok enfeksiyöz ajanın yanı sıra çevresel koşullar, bakım ve beslenme gibi etkenlerden de kaynaklanabilmektedir. Viral enfeksiyöz etkenlerin başında sıklıkla Bovine Rotavirus A, Cryptosporidium parvum, Bovine Coronavirus ve E. coli gibi etkenler tespit edilmektedir. Son y1llarda ise hem insanlarda hem de hayvanlarda önemli enfeksiyonlara neden olan Caliciviruslar yenidoğan buzağı ishallerinden sorumlu ajanlar olarak kabul edilmektedir. Caliciviruslardan Norovirus genogrup III ve Nebovirus "Bovine Enteric Caliciviruslar (BEC)" olarak tanımlanmaktadırlar. Bu etkenler günümüzde buzağı ishallerinin rutin teşhisinde yer almamasına karşın yapılan çalışmalar BEC'lerin tek başına ya da diğer enteropatojenler ile birlikte buzağı ishal olgularının gelişmesinde önemli rol oynadığını ortaya koymaktadır. Bu derleme ile Bovine Enteric Calicivirusların yapısal özellikleri ve bu virusların neden olduğu enfeksiyonlara ilişkin detaylı bilgilerin sunulması amaçlanmıştır.
\end{abstract}

Anahtar kelimeler: Bovine Norovirus, Buzağ ishalleri, Nebovirus

\section{Caliciviruses as Important Viral Agents of Newborn Calf Diarrhea}

\begin{abstract}
Summary: Newborn calf diarrhea, which is one of the important diseases of cattle breeding, could be caused by many infectious agents such as virus, bacteria, protozoon as well as environmental conditions, care, and nutrition. Bovine Rotavirus A, Cryptosporidium parvum, Bovine Coronavirus and E. coli are the most commonly detected viral infectious agents. Recently, Caliciviruses, which cause important infections in both humans and animals, are accepted as agents responsible for newborn calf diarrhea. Norovirus genogroup III and Nebovirus are identified as "Bovine Enteric Caliciviruses (BEC)". Although these enteropathogens are not included in the routine diagnosis of calf diarrhea, studies showed that BECs play an important role in calf diarrhea alone or along with the other enteropathogens. In this review, we aimed to present detailed information about structural features of Bovine Enteric Caliciviruses and their infections.
\end{abstract}

Keywords: Bovine Norovirus, Calf diarrhea, Nebovirus

\section{Giriş}

Yenidoğan buzağı ishalleri tüm dünyada gözlenen sığır yetiştiriciliğinin en önemli hastalıklardan birisidir. Doğrudan ya da dolaylı olarak önemli ekonomik kayıplara neden olan bu hastalık virus, bakteri, protozoon gibi birçok enfeksiyöz ajandan kaynaklanabildiği gibi, çevresel koşullar, bakım ve beslenme de bu hastalığa neden olabilmektedir [6]. Enfeksiyöz ajanlar tek başlarına bu hastalığa sebep olabildikleri gibi birden fazla enfeksiyöz ajanın tespit edilebildiği miks enfeksiyonlara da sıklıkla rastlanılmaktadır [9]. Her bir patojen ile oluşan enfeksiyonun prevalansı ve hastalığın insidensi bölgeden bölgeye, çiftliklerin yönetim sistemine ve sürü büyüklügüne göre farklılık göstermektedir [5].

Yenidoğan buzağı ishallerinde enfeksiyöz etken olarak çoğunlukla Bovine Rotavirus A (BRVA), Cryptosporidium parvum (C. parvum), Bovine
Coronavirus $(\mathrm{BCoV})$ ve $E$. coli tespit edilmektedir. Ancak günümüzde halen birçok klinik vakanın etiyolojisi tespit edilememektedir [35]. Son y1llarda ise "Bovine Enteric Caliciviruslar" yenidoğan buzağ 1 ishallerinden sorumlu ajanlar olarak kabul edilmektedir [5].

Uluslararas1 Virus Taksonomisi Komitesi'nin 2012 yılında yayımlanan dokuzuncu raporuna (9th Report of International Commitee on Taxonomy of Viruses) göre, Caliciviridae ailesi, "Vesivirus, Lagovirus, Norovirus, Sapovirus ve Nebovirus genuslarından oluşmaktadır (Şekil 1) [31]. Bu cinslerden yalnızca Norovirus (genogrup III) ve Nebovirus "Bovine Enteric Caliciviruslar (BEC)" olarak tanımlanmaktadırlar $[15,39]$. Bu derlemede Bovine Enteric Calicivirusların yapısal özellikleri ve BEC nedenli enfeksiyonlara ilişkin detaylı bilgilerin sunulması amaçlanmıştır. 


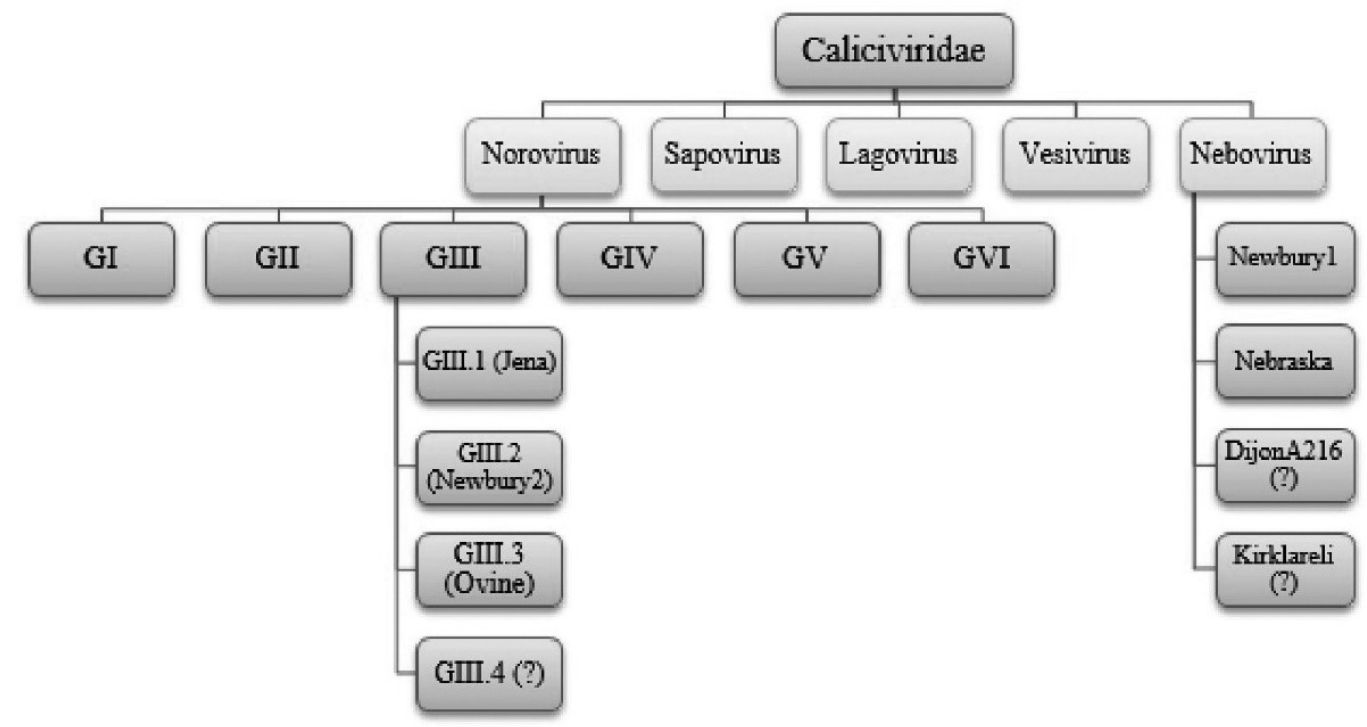

Şekil 1. Caliciviridae ailesi

\section{Tarihçe}

Noroviruslar ilk olarak 1968 y1lında, Norwalk, Ohio'da insanlardaki bir gastroenterit salgınında keşfedilmiştir. Bu salgında etiyolojik ajan olarak saptanan norovirus, "Norwalk virus" olarak adlandırılmış ve insan norovirusların prototip suşu olarak tanımlanmıştır [27]. İngiltere'de 1978 yılında ishalli bir buzağıda saptanan [54] ve Oliver ve ark. [36] tarafından moleküler karakterizasyonu yapılan "Newbury Agent 2 (Newbury2)" suşu ile 1980 y1lında Almanya'da izole edilen [20] ve 1999 y1lında moleküler karakterizasyonu yapılan [32] "Jena" suşu, günümüzde 2 farklı genotip olarak sınıfland1rılan sığır norovirusların (BoNoV) her bir genotipi için "prototip" viruslardır. Bu iki virus Norovirus genusunda Genogrup III içerisinde yer almaktadır $[32,39]$.

Tanımlanan diğer iki BEC ise "Newbury Agent 1 (Newbury1)" ve "Nebraska" suşlarıdır ve bu suşlar Neboviruslar içerisinde filogenetik olarak iki ayr1 "clade" oluşturmaktadır [37, 47]. Newbury1, Newbury2 ile birlikte 1978 y1lında İngiltere'de ishalli bir buzağıdan saptanmış [54] ve 1984 yılında karakterize edilmiştir [3,10]. Amerika' da 1980 y1lında tespit edilen Nebraska suşu ise Smiley ve ark. [47] tarafından Nebovirus olarak tanımlanmıştır.

\section{Calicivirusların Yapısı ve Sınıflandırma}

Caliciviruslar isimlerini elektron mikroskop altındaki karakteristik "fincan-şekilli” görüntülerinden alırlar [7]. Caliciviridae ailesindeki viruslar, ikozahedral simetriye sahip zarfsiz viruslardır [18]. Genom yaklaşık 7.4-8.3 kb büyüklügünde, pozitif polariteli, lineer tek iplikçilikli ssRNA'dan oluşur ve en az iki ya da üç ORF içerecek şekilde organize olmuştur [7]. Lagoviruslar, Sapoviruslar ve Neboviruslar iki ORF içerir ve ORF1 yapısal olmayan proteinleri ve temel kapsit proteinini (VP1) kodlarken; ORF2 minör yapısal proteini (VP2) kodlar. Vesiviruslar ve Noroviruslar ise üç ORF içermektedir ve VP1 ayr1 bir ORF olan ORF2 tarafindan kodlanırken, VP2 ORF3 tarafindan kodlanır [8, 18].

Noroviruslar (NoV) VP1 kapsit proteininin detaylı filogenetik analizlerine göre 6 "genogrup"tan (GI-GVI) oluşmaktadır [56]. GI içerisinde 9, GII'de 22, GIII'te 3, GIV, GV ve GVI'da 2'şer genotip bulunur [52]. Yakın zamanda Hong Kong'da bir köpekte saptanan NoV ise GVII olarak önerilmiştir [52]. BoNoV, kronolojik olarak bakıldığında bu genogruplar içerisinde ilk keşfedilen genogrup olan GIII'te yer almaktadır [32, 39].

NoV GIII içerisinde birbirlerinden antijenik olarak farklı üç genotip (GIII.1, GIII.2 ve GIII.3) bulunmaktadır [53]. GIII.1'in prototip suşu Jena, GIII.2'nin prototip suşu ise Newbury2'dir [36]. Yeni Zelanda'da koyunlardan ve domuzlardan al1nan dışk1 örneklerinde tespit edilen, GIII ile yakın ilişsili norovirus (Ov/NZL/2007/GIII.3/Norsewood30) GIII.3 olarak tanımlanmıştır [53]. Ayrıca Ar- 
jantin'de yapılan bir çalışmada saptanan bir suşun (Bo/AR/2012/B4881) ise muhtemel GIII.4 temsil ettiği bildirilmiştir [17].

Bugüne kadar sadece buzağılarda tespit edilen Neboviruslar, aslında 1980'lerden beri bilinmelerine karşın, Calicivirus ailesinde bir genus olarak nitelendirilmeleri oldukça yenidir [48]. Neboviruslarda iki polimeraz tipi tanımlanmıştır ve saptanan saha suşları, prototip viruslar (Bo/Newbury1/76/ UK ve Bo/Nebraska/80/US) dikkate alınarak Newbury1-benzeri ve Nebraska-benzeri olarak siniflandırılmaktadır. Ayrıca Neboviruslar arasındaki genetik farklılıklar nedeniyle yeni genotiplerin varlığına dair bildirimler de bulunmaktadır. Bu iki prototip virus dişında Kaplon ve ark. [29] muhtemel üçüncü bir genotipi temsil eden suşu (Bo/DijonA216/06/ FR) bildirmişlerdir. Neboviruslara ilgili tespitler ve moleküler karakterizasyon çalışmaları BoNoV'lara göre çok daha sınırlıdır. Bu nedenle gelecekte yapılacak çalışmalar Nebovirusların sınıflandırılmasına ilgili yeni veri ve yaklaşımları da ortaya koyacaktır. Bu bağlamda 3. bir genotip olarak önerilen $\mathrm{Bo} /$ DijonA216/06/FR suşu, ülkemizde Alkan ve ark. [1] tarafından şiddetli ishalli buzağılardan saptanan bir Calicivirus olan ve tam genom nükleotit benzerliği bakımında en yakın olarak Neboviruslara benzeyen (\%48) "Kırklareli virus" suşu ve gelecekte saptanması olası birçok farklı suşun yer aldığ 1 yeni sınıflandırma kriterlerinin oluşturulması da mümkün olabilecektir.

\section{Epidemiyoloji}

Noroviruslarla ilgili epidemiyolojik çalışmalar, örneklenen popülasyon, ülke, örneklemenin yapıldığ mevsim, vb. kriterlerin yanı sira BoNoV genotiplerinin (GIII.1 ve GIII.2) varlığı/yaygınlığına yönelik verileri de ortaya koymuştur. Bu epidemiyolojik verilere göre; BoNoV GIII.2'nin Avrupa ve Amerika'da endemik olduğu [12, 33, 49] ve genel olarak bakıldığında BoNoV GIII.2'nin GIII.1'den çok daha yaygın olduğu görülmektedir $[28,35,42$, $48,51]$. Günümüzde, Caliciviruslar içerisinde yeni tanımlanan bir genus olan Nebovirusların yaygınlığına dair çok sayıda bildirim bulunmamaktadır. Neboviruslar çoğunlukla Nebraska-benzeri genotip içinde sınıflandırılmış olup, Newbury1-benzeri genotip virus İngiltere dışında sadece Brezilya'da tespit edilmiştir [4].
Türkiye' de BEC enfeksiyonlarına ilgili bilgiler ise çok sınırlı düzeydedir. BoNoV ile ilgili olarak yapılan araştırmalarda $[19,50,55]$ ishalli buzağılarda GIII.2 genotipli BoNoV varlığ 1 \%1.7 - 8.5 oranlarında bildirilmiş olmasına karşın; yakın zamanda Karayel Hacıoğlu [30] tarafından yapılan çalışmada hem GIII.1 hem de GIII.2 varlığ belirlenmiştir. Ayrıca bu çalışma verileri, Türkiye'de daha önceki bildirimlere oranla BoNoV enfeksiyonlarının çok daha yaygın (\% 33.5) olduğunu da ortaya koymuştur.

Ülkemizde yenidoğan buzağılarda nebovirusların sorgulandığı iki çalışma da saptanan nebovirusların tümü Nebraska benzeri olarak tanımlanmış$\operatorname{tir}[30,50]$.

Buzağ1 ishalleri multifaktoriyel bir hastalıktır. $\mathrm{Bu}$ faktörlerin etkili olma durumları, doğum öncesi annelerin bakımı, buzağıların immünite durumları ve çevresel faktörler ile doğrudan ilişkilidir. Hastalığa neden olan patojenlerin bilinmesi, etkilenen çiftliklerin durumlarının belirlenmesi ve daha sonraki müdahalelerin geliştirilmesi için önemlidir [5, 9]. Yapılan çalışmalarda farklı ülkelerde sığırlarda değişen oranlarda BEC tespit edilmesine karşın, bu viruslar buzağı ishallerinin rutin teşhisinde halen birçok ülkede yer almamakta ve bu virusların sığır yetiştiriciliği üzerindeki etkileri tam olarak bilinmemektedir. Ancak her geçen gün elde edilen yeni epidemiyolojik veriler, BEC'lerin rutin tanı kapsamına alınması ihtiyacını ortaya koymaktadır [33, 49].

İshal olgularında BEC'lerin sorgulandığ 1 çalışmalarda farklı yaş aralıklarına ilişkin örneklemin olması, işletmenin yönetim şekli, biyolojik varyasyon, vb. nedenlerle, enfeksiyona duyarlı yaş gruplarına ilgili olarak her ne kadar önemli farkl1lıklar olmasa da çeşitli bilimsel değerlendirmelerde bulunulmuştur. $\mathrm{Bu}$ değerlendirmelerin birçoğu genel olarak doğum sonrasındaki ilk birkaç hafta için duyarlılığa işaret eden veriler olmakla birlikte, yaş faktörünün BoNoV için belirgin bir risk faktörü olmamasına karşın, pozitif örneklerin çoğunlukla genç hayvanlardan tespit edilmesi, yaş arttıkça riskin azaldığını ortaya koymaktadır $[30,35]$.

Enfeksiyöz etkenlere bağlı olarak yenidoğan buzağı ishallerinin görülme sıklığının bakım ve besleme koşullarının yeterince sağlanamaması, enfeksiyonlara direncin azalması, vb. nedenlerle özellikle soğuk mevsim koşullardan etkilenebileceği 
bilinmektedir. Yapılan çalışmalarda da, mevsimler itibarıla bazı oransal farklılıklar olmakla birlikte $[23,30,35,43]$ BEC'lerin tüm y1l boyunca tespit edilebileceği, özellikle entansif işletmeler için buzağıların yıl boyunca kapalı ortamda bulunmalarının ve bu ortam koşullarının etkili olabileceği bildirilmiştir [51].

\section{Bulaşma}

Enteric Calicivirusların temel bulaş yolu fekal-oral bulaşmadır [13, 56]. Calicivirusların doğada oldukça stabil ve belli ölçüde inaktivasyona dirençli olmaları, özellikle GIII.2 genotipli virusun dışkıda uzun süre saçılıyor olması [26], BoNoV'un yaygınlığının önemli göstergesi niteliğinde olan "yükssek seroprevalans" oranlarını açıklamaktadır [40, 49].

\section{Klinik Bulgular ve Patogenez}

BEC ile yapılan çalışmalar Murine NoV dışında başka bir norovirusun hücre kültüründe üretilememesi sebebiyle sınırlıdır [16]. BoNoV, diğer enteropatojenlerin de katıldığı miks enfeksiyonların yanı sıra tek başına da buzağılarda ishale neden olmaktadır [54]. Yapılan deneysel çalışmalar BoNoV GIII.1 ve GIII.2 prototip suşları arasında antijenik ve serolojik açıdan olduğu gibi enteropatojenik karakterleri açısından da farklılıkların bulunduğunu ortaya koymuştur [26, 41]. BoNoV GIII.2 ile enfekte buzağ1larda, GIII.1' e oranla daha uzun süre devam eden bir ishalin oluştuğu gözlenmiş [26]; buna karşın GIII.1 ile oluşan enfeksiyonların GIII.2 ile oluşan enfeksiyonlara oranla daha genç yaştaki hayvanlar1 etkileyebildiği ve kısa süreli yoğun ishale neden olduğu bildirilmiştir [3, 21, 41]. BoNoV prototip suşları olan "Jena" ya da "Newbury2" suşları ile enfekte olan buzağılardaki histopatolojik bulgular, villuslarda atrofi ve ince bağırsağın proksimalinde kriptlerde hiperplazi ile karakterizedir [3, 20]. Ancak, GIII.2 suşu ile yapılan çalışmada devam eden ishal ve uzun bir virus saçılımı gözlenmesine rağmen, Jena suşunun aksine bağırsak epitellerinde nekroz, villuslarda atrofi ve yangı lezyonları gibi belirgin akut bağırsak lezyonlarına rastlanmamıştır [26]. Yapılan bir deneysel çalışmada [41], GIII.1 ile inokulasyondan sonra, bu antijen yönünden pozitif epitel hücrelerine sahip uzun villusların saptanmas1, GIII.1 suşunun tüm enteroapsorbtif hücreleri enfekte ettiğini, yani Rotaviruslarda olduğu gibi sadece villusların uç kısmındaki hücrelere ya da Bovine
Toroviruslardaki gibi villusların alt kısmına karşı özel bir tropizim göstermediğini ortaya koymuştur. Bununla birlikte BoNoV ile yapılan çalışmalarda lezyonların yoğun olduğu kısımlar sıklıkla ince bağırsakların orta ve alt kısımları olarak belirlenmiştir.

Nebovirus enfeksiyonlarında ise genel olarak tüm buzağılarda, anoreksi, ileri derecede ishal, villuslarda atrofi, enzim aktivitesinde belirgin bir azalma ve ksiloz malabsorbsiyonu gözlenmektedir [3, $21,47]$. Nebovirus enfeksiyonlarında yoğun olarak ince bağırsağın üst kısımlarında lezyonların varlığı bildirilmiştir [21, 41]. Neboviruslara ilişkin çalışmalar, Newbury1 ile gelişen enfeksiyonun BoNoV Newbury2'den daha ağır klinik semptomlara neden olduğunu [3], buzağıların Nebraska virus ile enfeksiyonunun 3-4 günlük bir inkübasyondan sonra uzun süren bir ishalle sonuçlandığını göstermektedir [41]. BEC'lerin sistemik enfeksiyona neden olduğuna dair bilindiği kadarıyla bir bilgi bulunmamaktadır.

Norovirusların klinik olarak sağlıklı olan buzağlarda da tespit edildiğine dair bildirimler [25, 34, 45] bulunmasına rağmen, Nebovirusların buzağılar için patojenik olduğu bildirilmiştir [5, 21].

Buzağ1 ishallerinde miks enfeksiyonların varlığ1 s1k rastlanan bir durumdur. Her bir patojenin buzağ 1 ishallerinde oynadığı rol ve neden olduğu klinik seyir farklılık göstermektedir. Genellikle RVA ve $C$. parvum, buzağ 1 ishallerinden sorumlu etkenlerin başında gelmektedir [6]. İshalli buzağılarda BEC'lerin kayda değer oranda tespit edilmesi, çiftliklerde enterik hastalıklarla mücadele açısından bu viruslara ilişkin çalışmaların arttırılmasını gerektirmektedir. BEC'lerin yapılan deneysel çalışmalarda her ne kadar ishale neden olduğu kanıtlanmış $[21,26,39,41,47]$ olsa da bu virusların patojenitesi ve hastalık oluşturma mekanizmaları hakkında sınırlı bilgi bulunmaktadır. Bu nedenle sahada klinik tabloların gelişmesinde diğer enteropatojenlerin de rol almış olabileceği düşünülmektedir. Nitekim BEC'ler ile diğer enteropatojenlerin miks enfeksiyonlarına ilişkin tespitler oldukça fazladır $[6,14$, 42, 33].

\section{İmmunoloji}

Sığırlarda plasentanın yavruya maternal antikor geçişine izin vermemesi nedeniyle, yenidoğan buzağ1lar patojenlere karşı savunmasız bir şekilde doğ- 
maktadırlar. Bu nedenle buzağıların enterik etkenlere karşı dirençli olması, yüksek kalitede antikor içeren kolostrumun zamanında ve yeterli miktarda alınmasıyla yakından ilişkilidir. Genelde çiftlikler, birçok inekten alınan kolostrumu karıştırarak buzağılara vermesine rağmen, ideal olan her buzağının kendi annesinden kolostrumu almasidır [5].

BoNoV'un her iki genotipinin antijenik farkl1lığı nedeniyle heterolog antijene karşı çapraz reaksiyonun çok az ya da tespit edilemeyen düzeyde oldu$\breve{g u}$ [38], Norovirus ve Nebovirus prototip viruslar1 (Newbury1 ve Newbury2) ile yapılan çalışmalarda çapraz koruma olmadığı bildirilmiştir [3, 11]. Hayvan türlerine göre immun mekanizma değişmesine karşın insanlarda norovirusa karşı oluşan immun yanıtın benzerinin hayvanlarda da oluştuğu varsayılmaktadır [46]. NoV ile enfekte edilen insanlarda homolog suşa karşı uzun süreli bir immun yanıtın oluşmadığı, oluşan kısa süreli immun yanıtın da heterolog NoV suşlarına karşı yeterli koruma sağlamadığı bildirilmiştir [24]. Buzağılarda deneysel enfeksiyondan sonra oluşan homolog antikor yanıtının inokulasyonu izleyen birkaç hafta içinde maksimum titreye ulaştığı gözlenmiştir [21, 22]. Ancak, gelişen bu immun yanıtın süresiyle ilgili bir çalışma bulunmamaktadır.

BEC için canlı attenüe aşılar gibi kontrol stratejilerinin geliştirilmesindeki en önemli problem Murine NoV dışındaki NoV'ların hücre kültürlerinde üretilememesidir. $\mathrm{Bu}$ nedenle günümüzde, Virus Benzeri Partiküller (VLP), serolojik testleri geliştirmek ve NoV antijenisitesini belirlemek amacıyla kullanılmaktadır [12, 22, 33]. Aynı zamanda VLP'ler NoV aşı geliştirme çalışmaları için de birer alternatif oluşturmaktadır. BEC enfeksiyonu için, VLP'ler kullanılarak aşı geliştirilmesi yönünde görüş ve bilimsel çalışmalar [22] olmakla birlikte, halen ticari bir aşı bulunmamaktadır.

\section{Tanı}

BoNoV ve Nebovirus tanısı için uygun metotların geliştirilmesini zorlaştıran sebeplerin başında, söz konusu etkenlerin hücre kültürlerinde üretilememesi gelmektedir [16]. Günümüzde, kompleks 3D-hücre kültürü sistemlerinin GI ve GII insan NoV üretilmesinde kullanılmaya başlanmasının sonraki yıllarda BEC tespiti açısından yeni bir bakış açısı sunacağı düşünülmektedir [46].
NoV ve Nebovirusların tespitinde elektron mikroskop (EM) halen en geçerli temel araçlardan birisidir. Ancak, bu yöntemin yüksek miktarda virus yoğunluğuna ihtiyaç duyması (gram başına $>10^{6}$ virus partikülü) duyarlılığ 1 azaltan önemli bir faktördür [2]. Ayrıca, bu konuda oldukça tecrübeli araştırmacılara ihtiyaç duyulmaktadır. Bu yöntemin antikor antijen ilişkisine dayanan immunoelektron mikroskopi (IEM) ya da solid faz IEM gibi bir kaç çeşidi de bulunmaktadır $[5,46]$.

Son y1llarda immunoassay yöntemler ve RTPCR hem tanı hem de saptanan virusların moleküler karakterizasyonu için yaygın olarak kullanılmaktadır $[13,46]$. Norovirusların kapsit proteininin baculovirus sistemlerinde eksprese edilmesi ile yüksek miktarlarda VLP elde edilmekte ve bunlar immunoassaylarda antijen olarak kullanılmaktadır [33]. ELISA, bu testler içinde en yaygın olarak kullanılan testtir. Bu testler EM ye kıyasla oldukça duyarlıdır. Ancak, çabuk sonuç vermesi ve çok sayıda örneğin kolay işlemesine olanak sağlaması nedeniyle oldukça kullanışlı olan ELISA sistemlerinin diagnostik laboratuvarlarda kullanımları, düşük spesifiteleri, bu virusların antijenik farklılıkları nedeniyle duyarlıkta farklı1ıkların oluşması gibi faktörlerden etkilenmeleri olasıdır [13]. BoNoV ve Nebovirus çalışmalarında kullanılan antikor ve antijen ELISA geliştirildiğine dair bildirimler [12, 33, 40, 49] bulunmakla birlikte, günümüzde BoNoV ve Nebovirus için ticari bir kit bulunmamaktadır.

Caliciviruslara yönelik ilk moleküler çalışmalar insan NoV'a ilişkin olup, birçok epidemiyolojik çalışmanın yapılmasına kolaylık sağlamıştır. Genetik farklılıklar tüm NoV'ların tek bir primer çifti kullanılarak tespit edilmesini imkânsız kılmaktadır. Bu nedenle, bir hayvan türünde NoV varlığını tespit etmek için buna yönelik spesifik primerlerin kullanılması gerekmektedir [46]. Nitekim NoV ve Nebovirus arasında oldukça korunaklı bir bölge olan RdRp gen bölgesine yönelik tasarlanan primerler kullanılarak uygulanan RT-PCR metotu BEC'ları tespit etmek için son yıllarda yapılan çalışmalarda sıklıkla kullanılmaktadır [38, 42, 43, 48]. Ayrıca RT-PCR'a oranla daha duyarlı ve hızlı sonuç veren qRT-PCR kullanımının bildirimleri de [6, 25, 44, 55] son yıllarda sıklıkla yapılmaktadır. 


\section{Korunma}

Buzağı ishalleri multifaktoriyel bir hastalıktır. Hastalığa neden olan patojenlerin bilinmesi, etkilenen çiftliklerin durumlarının belirlenmesi ve daha sonraki müdahalelerin geliştirilmesi açısından önemlidir. Günümüzde, hastalıkların kontrolü ve önlenmesi, hem hayvan refahı hem de üretici açısından verimin arttırılmasını içermektedir [5]. Hastalıklardan korunmada hijyen kurallarının sağlanması, aşı uygulaması, vb. yöntemlere başvurulmaktadır. Günümüzde yenidoğan buzağılarda ishale neden olan BRVA, BCoV, C. perfiringens ve E. coli vb. patojenleri içeren aşılar bulunmaktadır. Ancak BEC içeren bir aşı bulunmamaktadır. Oysa BEC enfeksiyonlarının buzağı ishalleriyle ilgili oldukları kanıtlanmış olup, bu hastalıkta ayırıcı tanıda göz önünde bulundurulması gerekmektedir. Ayrıca, buzağıların ishale karşı etkin biçimde korunması için, bu virusların aşılara eklenmesi konusunda birçok araştırıcı hemfikirdir [13, 29]. Bu noktada yapılan bilimsel çalışmalar sonrası geliştirilmesi olası VLP aşıları ya da farklı biyoteknolojik aşılar, BEC enfeksiyonlardan korunmada önemli katkı sağlayacaktır.

\section{Sonuç}

Ülkemizde de BEC'lerin tek başına ya da diğer enteropatojenler ile birlikte buzağı ishal olgularının gelişmesinde önemli bir yer aldığ 1 değerlendirildiğinde, farklı populasyonların örneklendiği çalışmalar ile prevalans, saha viruslarının moleküler karakterizasyonu, ekonomik kayıpların hesaplanmasına yönelik analizlerin yapıldığı çalışmaların yanı sıra halen seroprevalans çalışmaları için geliştirilmiş ticari kitlerin bulunmadığı dikkate alınarak, VLP kullanılarak hazırlanacak ELISA sistemlerinin geliştirilmesi ve aşı hazırlama çalışmalarının yapılmas1 yönünde bilimsel çalışmalara ihtiyaç duyulmaktadır.

\section{Kaynaklar}

1. Alkan F, Karayel İ, Catella C, Bodnar L, Lanave G, Bányai K, Di Martino B, Decaro N, Buonavoglia C, Martella V, (2015). Identification of a Bovine Enteric Calicivirus, Kirklareli Virus, Distantly Related to Neboviruses, in Calves with Enteritis in Turkey. J Clin Microbiol. 53, 3614-3617.

2. Atmar RL, Estes MK, (2001). Diagnosis of noncultivatable gastroenteritis viruses, the human caliciviruses. Clin Microbiol Rev. 14, 15-37.
3. Bridger JC, Hall GA, Brown JF, (1984). Characterization of a calici-like virus (Newbury agent) found in association with astrovirus in bovine diarrhea. Infect Immun. 43, 133-138.

4. Candido M, Alencar ALF, Almeida-Queiroz SR, Buzinaro MG, Munin FS, Godoy SHS, Livonesi MC, Fernandes AM, Sousa RLM, (2016). First detection and molecular characterization of Nebovirus in Brazil. Epidemiol Infect 144, 1876-1878.

5. Cho YI, Yoon KJ, (2014). An overview of calf diarrhea infectious etiology, diagnosis, and intervention. J Vet Sci. $15,1-17$.

6. Cho YI, Han JI, Wang C, Cooper V, Schwartz K, Engelken T, Yoon KJ, (2013). Case-control study of microbiological etiology associated with calf diarrhea. Vet Microbiol. 166, 375-385.

7. Clarke IN, Lambden PR, (1997). The molecular biology of caliciviruses. J Gen Virol 78, 291-301.

8. Clarke IN, Lambden PR, (2000). Organization and Expression of Calicivirus Genes. J Infect Dis. 181, 309316.

9. Crouch CF, Oliver SP, Francis MJ, (2001). Serological, colostral and milk responses of cows vaccinated with a single dose of a combined vaccine against rotavirus, coronavirus and Escherichia coli F5 (K99). Vet Rec. 149, 105-108.

10. Dastjerdi AM, Green J, Gallimore CI, Brown DW, Bridger JC, (1999). The bovine Newbury agent-2 is genetically more closely related to human SRSVS than to animal caliciviruses. Virology. 254, 1-5.

11. Dastjerdi AM, Snodgrass DR, Bridger JC, (2000) Characterisation of the bovine enteric calici-like virus, Newbury agent 1. FEMS Microbiol Lett. 192, 125-131.

12. Deng Y, Batten CA, Liu BL, Lambden PR, Elschner M, Günther H, Otto P, Schnürch P, Eichhorn W, Herbst W, Clarke IN, (2003). Studies of epidemiology and seroprevalence of bovine noroviruses in Germany. J Clin Microbiol. 41, 2300-2305.

13. Di Felice E, Mauroy A, Pozzo FD, Thiry D, Ceci C, Di Martino B, Marsilio F, Thiry E, (2016). Bovine noroviruses: A missing component of calf diarrhoea diagnosis. Vet J. 207, 53-62.

14. Di Bartolo I, Ponterio E, Monini M, Ruggeri FM, (2011). A pilot survey of bovine norovirus in northern Italy. Vet Rec. 169, 73.

15. Di Martino B, Di Profio F, Martella V, Ceci C, Marsilio $\mathrm{F}$, (2011). Evidence for recombination in neboviruses. Vet Microbiol. 153, 367-372.

16. Duizer E, Schwab KJ, Neill FH, Atmar RL, Koopmans MPG, Estes MK, (2004). Laboratory efforts to cultivate noroviruses. J Gen Virol. 85, 79-87.

17. Ferragut F, Vega CG, Mauroy A, Conceição-Neto N, Zeller M, Heylen E, Uriarte EL, Bilbao G, Bok M, Matthijnssens J, Thiry E, Badaracco A, Parreño V, (2016). Molecular detection of bovine Noroviruses in Argentinean dairy calves. Circulation of a tentative new genotype. Infect Genet Evol. 40, 144-150. 
18. Green KY, Ando T, Balayan MS, Berke T, Clarke IN, Estes MK, Matson DO, Nakata S, Neill JD, Studdert MJ, Thiel HJ, (2000). Taxonomy of the caliciviruses. J Infect Dis. $181,322-330$.

19. Gülaçtı I, Sözdutmaz I, Işıdan H, (2016). Molecular Characterization of the Bovine Noroviruses from Diarrhoeic Calves in Turkey 2. Turk J Vet Anim Sci 40: $1-6$.

20. Günther H, Otto P, (1987). Diarrhea in young calves. 7." Zackenvirus"(Jena agent 117/80)--a new diarrhea pathogen in calves. Arch Exp Veterinarmed. 41, 934.

21. Hall GA, Bridger JC, Brooker BE, Parsons KR, Ormerod E, (1984). Lesions of gnotobiotic calves experimentally infected with a calicivirus-like (Newbury) agent. Vet Pathol. 21, 208-215.

22. Han MG, Wang Q, Smiley JR, Change KO, Saif LJ, (2005). Self-assembly of the recombinant capsid protein of a bovine norovirus (BoNV) into virus-like particles and evaluation of cross-reactivity of BoNV with human noroviruses. J Clin Microbiol. 43, 778-785.

23. Hassine-Zaafrane M, Kaplon J, Sdiri-Loulizi K, Aouni Z, Pothier P, Aouni M, Ambert-Balay K, (2012). Molecular prevalence of bovine noroviruses and neboviruses detected in central-eastern Tunisia. Arch Virol. 157, 1599-1604.

24. Johnson PC, Mathewson JJ, DuPont HL, Greenberg HB, (1990). Multiple-challenge study of host susceptibility to norwalk gastroenteritis in US adults. J Infect Dis. 161, 1821.

25. Jor E, Myrmel M, Jonassen CM, (2010). SYBR Green based real-time RT-PCR assay for detection and genotype prediction of bovine noroviruses and assessment of clinical significance in Norway. J Virol Methods. 169, 1-7.

26. Jung K, Scheuer KA, Zhang Z, Wang Q, Saif LJ, (2014). Pathogenesis of GIII.2 bovine norovirus, CV186-OH/00/ US strain in gnotobiotic calves. Vet Microbiol. 168, 202207.

27. Kapikian AZ, (2000). The discovery of the 27-nm Norwalk virus: an historic perspective. J Infect Dis. 181, 295-302.

28. Kaplon J, Fremy C, Bernard S, Rehby L, Aho S, Pothier $\mathrm{P}$, Ambert-Balay K, (2013). Impact of rotavirus vaccine on rotavirus genotypes and caliciviruses circulating in French cattle. Vaccine. 31, 2433-2440.

29. Kaplon J, Guenau E, Asdrubal P, Pothier P, Ambert-Balay $\mathrm{K}$, (2011). Possible novel Nebovirus genotype in cattle, France. Emerg Infect Dis. 17, 1120-1123.

30. Karayel Hacığlu, (2016). Buzağılarda Enterik Calicivirus (BEC) Enfeksiyonlarının Moleküler Epidemiyolojisi. Doktora Tezi, AÜ Sağlık Bilimleri Enstitüsü, Ankara.

31. Kroneman A, Vega E, Vennema H, Vinjé J, White PA, Hansman G, Green K, Martella V, Katayama K, Koopmans M, (2013). Proposal for a unified norovirus nomenclature and genotyping. Arch Virol. 158, 2059-2068.

32. Liu BL, Lambden PR, Günther H, Otto P, Elschner M, Clarke IN, (1999). Molecular characterization of a bovine enteric calicivirus: relationship to the Norwalk-like viruses. J Virol. 73, 819-825.
33. Mauroy A, Scipioni A, Mathijs E, Saegerman C, Mast J, Bridger JC, Ziant D, Thys C, Thiry E, (2009). Epidemiological study of bovine norovirus infection by RT-PCR and a VLP-based antibody ELISA. Vet Microbiol. 137, 243-251.

34. Mijovski JZ, Poljšak-Prijatelj M, Steyer A, BarličMaganja D, Koren S, (2010). Detection and molecular characterisation of noroviruses and sapoviruses in asymptomatic swine and cattle in Slovenian farms. Infect Genet Evol. 10, 413-420.

35. Milnes AS, Binns SH., Oliver SL., Bridger JC, (2007). Retrospective study of noroviruses in samples of diarrhoea from cattle, using the Veterinary Laboratories Agency's Farmfile database. Vet Rec. 160, 326-330.

36. Oliver SL, Asobayire E, Charpilienne A, Cohen J, Bridger JC, (2007a). Complete genomic characterization and antigenic relatedness of genogroup III, genotype 2 bovine noroviruses. Arch Virol. 152, 257-272.

37. Oliver SL, Asobayire E, Dastjerdi AM, Bridger JC, (2006a). Genomic characterization of the unclassified bovine enteric virus Newbury agent-1 (Newburyl) endorses a new genus in the family Caliciviridae. Virology 350, 240-250.

38. Oliver SL, Batten CA, Deng Y, Elschner M, Otto P, Charpilienne A, Clarke IN, Bridger JC, Lambden PR, (2006b). Genotype 1 and Genotype 2 Bovine Noroviruses Are Antigenically Distinct but Share a Cross-Reactive Epitope with Human Noroviruses. J Clin Microbiol. 44, 992-998.

39. Oliver SL, Dastjerdi AM, Wong S, El-Attar L, Gallimore C, Brown DWG, Green J, Bridger JC, (2003). Molecular characterization of bovine enteric caliciviruses: a distinct third genogroup of noroviruses (Norwalk-like viruses) unlikely to be of risk to humans. J Virol. 77, 2789-2798.

40. Oliver SL, Wood E, Asobayire E, Wathes DC, Brickell JS, Elschner M, Otto P, Lambden PR, Clarke IN, Bridger JC, (2007b). Serotype 1 and 2 bovine noroviruses are endemic in cattle in the United Kingdom and Germany. J Clin Microbiol. 45, 3050-3052.

41. Otto PH, Clarke IN, Lambden PR, Salim O, Reetz J, LieblerTenorio EM, (2011). Infection of Calves with Bovine Norovirus GIII.1 Strain Jena Virus: an Experimental Model To Study the Pathogenesis of Norovirus Infection. J Virol. 85, 12013-12021.

42. Park SI, Jeong C, Kim HH, Park SH, Park SJ, Hyun BH, Yang DK, Kim SK, Kang MI, Cho KO, (2007). Molecular epidemiology of bovine noroviruses in South Korea. Vet Microbiol. 124, 125-133.

43. Park SI, Jeong C, Park SJ, Kim HH, Jeong YJ, Hyun BH, Chun YH, Kang MI, Cho KO, (2008). Molecular detection and characterization of unclassified bovine enteric caliciviruses in South Korea. Vet Microbiol. 130, 371-379.

44. Park SI, Park DH, Saif LJ, Jeong YJ, Shin DJ, Chun YH, Park SJ, Kim HJ, Hosmillo M, Kwon HJ, Kang MI, Cho KO, (2009). Development of SYBR Green real-time RT$P C R$ for rapid detection, quantitation and diagnosis of unclassified bovine enteric calicivirus. J Virol Methods. $159,64-68$. 
45. Reuter G, Pankovics P, Egyed L, (2009). Detection of genotype 1 and 2 bovine noroviruses in Hungary. Vet Rec. $165,537-538$.

46. Scipioni A, Mauroy A, Vinjé J, Thiry E, (2008). Animal noroviruses. Vet J. 178, 32-45.

47. Smiley JR, Chang KO, Hayes J, Vinje J, Saif LJ, (2002). Characterization of an enteropathogenic bovine calicivirus representing a potentially new calicivirus genus. $\mathrm{J}$ Virol. 76, 10089-10098.

48. Smiley JR, Hoet AE, Traven M, Tsunemitsu H, Saif LJ, (2003). Reverse transcription-PCR assays for detection of bovine enteric caliciviruses (BEC) and analysis of the genetic relationships among $B E C$ and human caliciviruses. $\mathrm{J}$ Clin Microbiol. 41, 3089-3099.

49. Thomas C, Jung K, Han MG, Hoet A, Scheuer K, Wang Q, Saif LJ, (2014). Retrospective serosurveillance of bovine norovirus (GIII.2) and nebovirus in cattle from selected feedlots and a veal calf farm in 1999 to 2001 in the United States. Arch Virol. 159, 83-90.

50. Turan T, Işıdan H, Atasoy MO, Irehan B, (2018). Detection and molecular analysis of bovine enteric norovirus and nebovirus in Turkey. J Vet Res. 62, 129-135.
51. Van der Poel WHM, van der Heide R, Verschoor F, Gelderblom H, Vinjé J, Koopmans MPG, (2003). Epidemiology of Norwalk-like virus infections in cattle in The Netherlands. Vet Microbiol. 92, 297-309.

52. Vinjé J (2015) Advances in Laboratory Methods for Detection and Typing of Norovirus. J Clin Microbiol 53: 373-381.

53. Wolf S, Williamson W, Hewitt J, Lin S, Rivera-Aban M, Ball A, Scholes P, Savill M, Greening GE, (2009). Molecular detection of norovirus in sheep and pigs in New Zealand farms. Vet Microbiol. 133, 184-189.

54. Woode GN, Bridger JC, (1978). Isolation of Small Viruses Resembling Astroviruses and Caliciviruses from Acute Enteritis of Calves. J Med Microbiol. 11, 441-452.

55. Yilmaz H, Turan N, Altan E, Bostan K, Yilmaz A, Helps CR, Cho KO, (2011). First report on the phylogeny of bovine norovirus in Turkey. Arch Virol. 156, 143-147.

56. Zheng DP, Ando T, Fankhauser RL, Beard RS, Glass RI, Monroe SS, (2006). Norovirus classification and proposed strain nomenclature. Virology. 346, 312-323. 